\title{
Left ventricular hypertrophy: is it really?
}

\author{
J Ronald Mikolich ${ }^{1,2^{*}}$, John Lisko ${ }^{1,2}$, Nicholas C Boniface ${ }^{2}$, Brandon M Mikolich ${ }^{1,2}$ \\ From 16th Annual SCMR Scientific Sessions \\ San Francisco, CA, USA. 31 January - 3 February 2013
}

\section{Background}

Patients with left ventricular hypertrophy (LVH), typically assessed by $2 \mathrm{D}$ echocardiography, are at a greater risk for heart failure and sudden cardiac death. An accurate diagnosis of $\mathrm{LVH}$ is essential to clinical evaluation and treatment. However, 2D echo has inferior spatial resolution and less than optimal measurement positioning, relative to cardiac MRI. This "real-world" study, based on finalized 2D echo reports, sought to compare assessment of $\mathrm{LVH}$ on $2 \mathrm{D}$ echo to results by cardiac MRI (cMRI).

\section{Methods}

All 1,255 patients in an institutional cardiac MRI database were queried for a 2D echo study within 6 months of the cMRI study. Patient 2D and cMRI reports were then classified as either negative (no evidence of LVH on the final report) or positive (evidence of LVH on the final report). Antero-septal and infero-posterior LV wall thickness dimensions were recorded for both imaging modalities for all patients, and a paired-sample t-test was used for statistical comparison.

\section{Results}

Six hundred twenty-four patients in the cMRI database had both 2D echo and cMRI exams. Of these 624 patients, 280 patients had a diagnosis of LVH on the $2 \mathrm{D}$ echo report. On $2 \mathrm{D}$ echo the mean antero-septal LV wall thickness was $1.30 \pm 0.20 \mathrm{~cm}$, while on cMRI the mean anteroseptal LV wall thickness was $1.20 \pm 0.31 \mathrm{~cm}(\mathrm{p}<0.001)$. On $2 \mathrm{D}$ echo the mean infero-posterior LV wall thickness was $1.29 \pm 0.17 \mathrm{~cm}$, while comparatively the mean infero-posterior LV wall thickness by cMRI was $0.94 \pm 0.21 \mathrm{~cm}$ $(\mathrm{p}<0.001)$. Of the 280 patients with a diagnosis of LVH on the $2 \mathrm{D}$ echo report, the diagnosis of LVH was corroborated by cMRI in only 43 cases.

${ }^{1}$ Northeast Ohio Medical University, Rootstown, OH, USA

Full list of author information is available at the end of the article

\section{Conclusions}

There is low concordance between a diagnosis of $\mathrm{LVH}$ by $2 \mathrm{D}$ echo when compared to cMRI, as derived from final imaging reports in an active clinical practice. Because of better spatial resolution, less restricted viewing window and more accurate positioning of LV wall thickness dimensions, cMRI may be a more appropriate imaging modality for assessing left ventricular hypertrophy in a "real-world" setting.

\section{Funding}

None. Not applicable.

Author details

${ }^{1}$ Northeast Ohio Medical University, Rootstown, OH, USA. ${ }^{2}$ Sharon Regional Health System, Hermitage, PA, USA.

Published: 30 January 2013

doi:10.1186/1532-429X-15-S1-E107

Cite this article as: Mikolich et al: Left ventricular hypertrophy: is it really? Journal of Cardiovascular Magnetic Resonance 2013 15(Suppl 1):E107.

Submit your next manuscript to BioMed Central and take full advantage of:

- Convenient online submission

- Thorough peer review

- No space constraints or color figure charges

- Immediate publication on acceptance

- Inclusion in PubMed, CAS, Scopus and Google Scholar

- Research which is freely available for redistribution 